\title{
The effect of cognitive task difficulty on humor ratings of captioned cartoons
}

\author{
DONALD B. REUTENER and ANNE E. KAZAK \\ Smith College, Northampton, Massachusetts 01060
}

\begin{abstract}
Subjects who engaged in a taxing cognitive task perceived complex captioned cartoons to be less humorous than those who engaged in an easy task. Task complexity had little effect, however, on perceived humor of simple or political captioned cartoons. The results lend support to Suls' two-stage model for the appreciation of jokes.
\end{abstract}

A highly subjective and little understood aspect of human behavior is humor appreciation. Even though empirical research in the area has been conducted over a number of years (Treadwell, 1967) and numerous models have been developed to explain humor (Goldstein \& McGhee, 1972), there appears to be little empirical support for any of them.

Suls (1972, p. 98) cites a technique suggested by Brock and Goldstein which might lead to a better understanding of the effect of cognitive factors on the appreciation of humor. On the basis of his two-stage model for the appreciation of humor, Suls predicts that subjects who have been cognitively taxed should prefer less complex humor. This experiment was designed to test that prediction using a form of Brock and Goldstein's suggested technique of giving subjects either cognitively easy or difficult tasks and assessing the effects of the tasks on humor of varying complexity.

\section{METHOD}

\section{Subjects and Apparatus}

The subjects were 40 undergraduate women enrolled at Smith College who volunteered to participate in the experiment.

Cartoon stimuli consisted of 60 cartoons glued to separate pieces of white construction paper. There were 15 cartoons in each of four humor categories. The categories were defined by the source of the cartoon. Cartoons categorized as simple came from syndicated comic strips such as Andy Capp, Red Eye, Nancy, and others found in most daily papers, and were characterized by plays on words and puns.

Complex cartoons were defined as those found in the "New Yorker;" they were more subtle in character and required a broader base of knowledge for comprehension than the cartoons in the simple humor category.

Political cartoons were relevant to current events of April and May 1974, and were drawn predominately from "Newsweek."

The cartoons included in the category of mixed humor consisted of representative cartoons from the other three categories.

A complete deck of playing cards was used for the easy task,

Reprint requests should be sent to Donald B. Reutener, Department of Psychology, Smith College, Northampton, Mass. 01060. This paper was sponsored by Barbara S. Musgrave, who takes full editorial responsibility for its contents. which consisted of placing the cards in ascending order by suits. A nine-piece puzzle, The Uptight Spider ${ }^{1}$, which is extremely difficult to put together correctly, was used as the difficult task.

\section{Procedure}

Subjects were randomly assigned to one of eight groups. In four of the groups, subjects engaged in the simple task and then rated for humor content simple, complex, political, or mixed cartoons. Subjects in the other four groups engaged in the difficult task and then rated for humor content cartoons in the same four categories.

Subjects read instructions which described either the easy or difficult task and then tried to complete the task within a 5-min period. At the conclusion of the 5-min period, subjects read a second set of instructions which described the procedure for rating the captioned cartoons, which they then did. Subjects were asked to circle the number on a scale which they felt best expressed the degree of humor content perceived in each cartoon. The scale ranged from 1 (low humor content) to 10 (high humor content). Each subject received the 15 cartoons in her category in an order determined by a table of random numbers.

\section{RESULTS}

The four categories of cartoons were not rated by subjects as being different in humor content $(F=2.27$, $\mathrm{df}=3 / 32, p>.05$ ). All four categories appeared to be equally funny. The means for the different types of humor ranged from 4.24 to 5.39 , clustering right below the midpoint of the humor scale.

The difficulty of the task did lead to significantly different humor ratings. The cartoons were rated as significantly less funny after the difficult task than after the easy task $(F=12.99$, df $=1 / 32, p<.005)$. The mean rating after the easy task is 5.48 and after the difficult task 4.32 .

The interaction between type of humor and difficulty of task is also significant $(F=5.13, d f=3 / 32, p<.05)$. As can be seen in Table 1, complex humor was rated as far less funny after the difficult task than after the easy task.

Preplanned $t$ tests indicated that the humor ratings for the complex humor/easy task were signigicantly higher than the humor ratings for the complex humor/ difficult task $(t=4.12, d f=8, p<.01)$. There were no 
Table 1

Mean Ratings of Captioned Cartoons for Each Experimental Condition

\begin{tabular}{lcccc}
- & Simple & Complex & Political & Mixed \\
\hline Easy Task & 4.96 & 5.84 & 5.39 & 5.72 \\
Difficult Task & 5.20 & 2.64 & 4.36 & 5.07 \\
\hline
\end{tabular}

significant differences for the three other similar comparisons.

A Duncan multiple range test showed that the ratings for complex humor after the difficult task were significantly different $(p<.05)$ from the other three types of humor after the difficult task, while the other three types of humor were not significantly different from each other.

\section{DISCUSSION}

The major finding of the study is that cartoons from the "New Yorker," which were assumed to be more complex than the cartoons from other sources, were perceived by subjects to be less funny after the difficult task than after the easy task. Cartoons from all other sources were rated about the same after either the easy or difficult task, so the degree of task difficulty seems to have no effect on the perceived humor of a cartoon if it is a simple or political one.

It appears, then, that Suls' prediction is correct. Subjects who had been cognitively taxed did prefer simpler humor. Specifically, in this experiment, complex cartoons were not perceived as being so funny by subjects who had engaged in a difficult task as they were by subjects who had engaged in a simple task. In addition, the task difficulty did not seem to have an effect on perceived humor, as indicated by the ratings, on any type of captioned cartoon other than the complex. This result seems to mirror our own experience, in that comic strips in the funny paper seem more enjoyable than the "New Yorker" after a hard day of classes.

The experimental procedure used in this experiment, with a few modifications, particularly in the sensitivity of the rating scale, might be useful for arranging cartoons or other types of humorous material on a continuum of complexity.

\section{REFERENCES}

Goldstein. J. H., \& McGheE, P. The psychology of humor. New York: Academic Press, 1972.

Suls. J. M. A two-stage model for the appreciation of jokes and cartoons: An information-processing analysis. In J. H. Goldstein. \& P. McGhee (Eds.), The psychology of humor. New York: Academic Press. 1972.

TREADWELL, V. Bibliography of empirical studies of wit and humor. Psychological Reports, 1967, 20. 1079-1083.

\section{NOTE}

1. The uptight spider, Peterson Games, Sacramento, California, 1972.

(Received for publication November 17. 1975.) 